\title{
Phenolic compounds change in Table Olives
}

\author{
Gökçen İzli* \\ *Faculty of Natural Sciences Architecture and Engineering, University of Bursa Technical, Turkey
}

Submission: October 13, 2017; Published: November 10, 2017

*Corresponding author: Gökçen İzli, Department of Food Engineering, Faculty of Natural Sciences, Architecture and Engineering, University of Bursa Technical, Bursa, 16190, Turkey, Tel: +90-22430035 02; Fax: +90-224300 34 19; e-mail: gokcen.izli@btu.edu.tr

\begin{abstract}
The olive and its products, basis components of the Mediterranean diet, are excellent food sources of phenolic compounds. Because of a bitter component oleuropein, olive fruits undergo debittering process. During this process, physical, chemical and biochemical changes occur in olives. However, due to having a very complicated structure of phenolic compounds, the excess of olive varieties, the geographical, agricultural factors, the degree of maturity of the fruits and the differences in the production methods cause various difficulties in fully expressing the data concerning the phenolic compounds. The present review provided information about the phenolic compounds in olive and table olives.
\end{abstract}

\section{Introduction}

Olive is the basis component of the Mediterranean diet. The positive effects on human health (reduction in cardiovascular disease and certain types of cancerous diseases) of the consumption of olives and their products, beside the unsaturated fatty acid content rich in oleic acid, are related to phenolic compounds. Olive has high antioxidant activity due to its natural phenolic compounds and is characterized as a functional food. Also, phenolic compounds in olive are important for taste, aroma, color and shelf life of the final product $[1,2]$.

The phenolic compounds in the olive fruit are a complicated structure, and their chemical structures and properties has not been explained well. They are mostly located the fruit peel and seed. There are a large number of phenolic compounds ranging from simple to more complex structure which have more than one aromatic ring. Complex phenolic compounds, in other words polyphenols, are the result of the incorporation of simple phenolic compounds into sugars (for example, glycosides). Although the chemical properties of olive phenolic compounds different, most of them are watersoluble. Main classes of phenolic compounds that make up $1-3 \%$ of fresh fruit weight are phenolic acids, phenolic alcohols, flavonoids and secoiridoids. At least thirty different simple and complex phenolic compounds have been identified and quantified in olive fruit and table olives belong to phenolic acids (gallic, caffeic, ferulic, vanillic, p-hydroxybenzoic, protocatechuic, p-coumaric, syringic and sinapic acids), phenolic alcohols (hydroxytyrosol and tyrosol), flavonoids (rutin, luteolin, luteolin-7-glucoside, apigenin-7-glucoside, cyanidin-3-glucoside, cyanidin-3-rutinoside and quercetin-3 rhamnoside) and secoiridoids class (oleuropein, verbascoside, ligstrosideand demethyloleuropein) [3-5].

The composition and amount of phenolic compounds in the olive depends on the olive variety, the degree of maturity, the soil and climatic conditions where the cultivation is carried out, the position of the olive on the tree, root status of the tree and the agricultural practices such as irrigation and fertilization related to growing. Moreover, processing of olives into table olives changes the composition of the phenolic compounds significantly. All olive varieties can be processed as table olives. However, table olives are produced by using different production methods for the consumption in order not to make any difference in quality. It has been reported that the olive phenolic compounds show significant quantitative and quantitative changes, and their ratios in the olive decrease due to the various mechanisms (result of hydrolysis of glycosides, oxidation and polymerization of free phenolic compounds) in the processes applied in this process. Oleuropein, a secoiridoid glucoside, is the predominant phenolic compound which is responsible for the bitterness of untreated olive, whereas hydroxytyrosol, resulting in the breakdown of oleuropein in the fermentation process of olives, is the predominant phenolic compound in the final product [5-7].

In the our study (not published yet), the phenolic compounds of Gemlik variety olive obtained from five different provinces of Bursa and the table olives that processed by dry- 
salted, brine and rapid (olive fruit treated with a dilute sodium hydroxide solution) methods have been determined. According to the results, hydroxytyrosol was determined as the highest amount of phenolic compound in all olive samples. Although the amounts of hydroxytyrosol, tyrosol and caffeic acid were higher than in the fresh olives in all three production methods for the first days of fermentation, it was determined that the amount of each phenolic compound decreased at the end of process. The increase in the amount of these three phenolic compounds compared to the fresh olive in the first days of fermentation can be explained by the formation of hydroxytyrosol, tyrosol and caffeic acid, respectively as a result of the breakdown of oleuropein, ligstroside and verbascoside. It was determined that the loss of the total amount of phenolic was approximately $68 \%$ in the dry-salted method, $54 \%$ in the brine method and $60 \%$ in the rapid method compared to the raw material. It is believed that the brine method, which is a natural processing method, does not require a lot of processing, so that the losses in the phenolic compounds are found less. On the other hand, the highest decrease in the total amount of phenolic compounds was determined in the method of dry-salted olives which is also a natural method. In this method, it is assumed that the phenolic compounds in the olive fruit which is directly treated with dry salt are removed by important water loss occurred during process. Sodium hydroxide application is thought to be effective in the decrease of the total amount of phenolic compounds of olives processed by the rapid method. The loss of the total amount of phenolic compounds of olives belonging to five different localities was found as $57-65 \%$ compared to the raw material at the end of the fermentation. It has been reported that the shell permeability is the main factor of passing phenolic compounds from olive fruit to the brine [6]. For this reason, the olive variety which was resulted with the least amount of loss (57\%) might have less shell permeability.

\section{References}

1. Bianco A, Uccella N (2000) Biophenoliccomponents of olives. Food Research International 33: 475-485.

2. Uylaser V, Ylldız G (2014) The historical development and nutritional importance of olive and olive oil constituted an important part of the Mediterranean diet. Crit Rev Food Sci Nutr 54(8): 1092-1110.

3. Bianchi G (2003) Lipids and phenols in table olives. European Journal of Lipid Science and Technology 105: 229-242.

4. Esti M, Cinquanta L, La Notte E (1998) Phenolic compounds in different olive varieties. J Agric Food Chem 46(1): 32-35.

5. Vinha A F, Ferreres F, Silva B M, Valentao P, GonçalvesA, et al. (2005) Phenolic profiles Portuguese olive fruits (Oleaeuropea L) influences of cultivar and geographical origin. Food Chemistry 89: 561-568.

6. Brenes M, Romero C, Garcia P, Garrido A (1995) Effect of pH on the colour formed by Fe-phenolic complex in ripe olives. Journal of the Science of Food and Agriculture 67: 35-41.

7. Charoenprasert S, Mitchell A (2012) Factors influencing phenolic compounds in table olives (Oleaeuropaea). Journal of Agricultural and Food Chemistry 60: 7081-7095.

\section{Your next submission with Juniper Publishers will reach you the below assets}

- Quality Editorial service

- Swift Peer Review

- Reprints availability

- E-prints Service

- Manuscript Podcast for convenient understanding

- Global attainment for your research

- Manuscript accessibility in different formats ( Pdf, E-pub, Full Text, Audio)

- Unceasing customer service

Track the below URL for one-step submission https://juniperpublishers.com/online-submission.php 